\title{
A SUPPORT TOOL FOR ASSESSING THE RISKS OF HEAVY LIFT VESSEL LOGISTICS IN THE INSTALLATION OF OFFSHORE WIND FARMS
}

\author{
E Barlow and D Tezcaner Ozturk, Department of Naval Architecture, Ocean and Marine Engineering and Department of \\ Management Science, University of Strathclyde, UK \\ AH Day and E Boulougouris, Department of Naval Architecture, Ocean and Marine Engineering, University of Strathclyde, \\ UK \\ M Revie and K Akartunali, Department of Management Science, University of Strathclyde, UK
}

\section{SUMMARY}

Semi-submersible heavy lift vessels (HLVs) are currently the main option for the installation of electrical substation platforms on offshore wind farms. As sites move further offshore installation operations are subject to harsher weather conditions which results in increased uncertainty over the cost and duration of the installation. Assessing the comparative risks associated with logistical decisions and identifying the best course of action is therefore a challenging problem. This study describes a support tool developed through collaboration between industry and academia which is designed to aid decision makers by providing improved understanding of the risks associated with logistical decisions. A case study of a realistic offshore wind farm installation is utilised to explore the impact of key HLV logistical decisions on the cost and duration of the installation of offshore substations.

\section{INTRODUCTION}

The installed capacity of offshore wind energy has been steadily increasing in Europe over the last five to ten years, with the majority of offshore wind farms (OWFs) developed in the North Sea [6]. Since 2008 the UK has had the largest installed offshore wind capacity worldwide [5]. As of mid-2013 this stood at $4.7 \mathrm{GW}$ capacity in operational or commissioned OWF sites [9], and the UK government has targeted an operational capacity of $16 \mathrm{GW}$ by 2020 [15]. To meet this target OWF development has progressed to the Round 3 and Scottish territorial OWF sites. These sites are further from shore which enables large scale OWFs to be developed, with the number of wind turbines (WTs) typically over a hundred; however, developing these sites gives rise to a new set of challenges. Being situated further from shore these sites are exposed to more severe weather conditions, which increases the complexity of offshore operations and increases the uncertainty around managing these operations. Additionally, the large scale of these developments amplifies the impact of any operational decisions as these are repeated many times across the OWF site.

The UK government's industry-led Offshore Wind Cost Reduction Task Force has identified installation and logistics as an area where substantial cost-reductions can be achieved through innovation [8]. The installation of an OWF is particularly susceptible to the new challenges arising through developments being larger in size and further offshore. Challenges facing decision makers in the planning and installation stage of an OWF include determining what impact the selection of ports and vessels to be utilised during the installation will have on the length of the installation process and the resulting costs. As the duration of installation operations are subject to the uncertain weather conditions as well as the specific vessels used for the installation, assessing the comparative benefits of two installation scenarios over an entire OWF installation is challenging. An improved understanding of the impact of logistical decisions on the duration and costs of an OWF installation is therefore required to enable cost-efficient installation scenarios to be identified.

There are several major components which comprise an OWF, and the installation of each component requires specific capabilities from the installation vessel(s) used. An overview of the different components and their associated vessel requirements can be found in [5]. For larger sites with sufficient generating capacity which are located sufficiently far from shore a small number of offshore substation platforms (OSPs) may be included in the OWF layout. These structures collect the power generated by the wind turbines, in some cases converting this to direct current flow, before transmission to the onshore grid through a series of export cables. OSPs house electrical components including voltage transformers within a topside structure which is built upon foundations installed on the seabed. Various types of foundations have been used to-date depending on several factors including the capacity of the topside, the water depth and soil conditions. For larger topsides the most appropriate type of foundation is likely to be a piledriven jacket which is a steel lattice tower secured to the seabed. A single OSP may comprise multiple topside sections which are combined on-site, situated upon one or two jackets, each secured with multiple piles. The OSP topsides and jackets are likely to be the heaviest components of an OWF; topsides can potentially weigh in excess of 10,000 tonnes and require specialist heavy lift vessels (HLVs) for their installation. A small number of HLVs have been utilised in the installation of all OSPs included in European OWFs to-date and these vessels are in high-demand with additional competition for demand from the oil and gas industry. As a result these vessels command substantial day-rates and the costs of the OSP installation can comprise a significant portion of the overall installation costs. To minimise costs it is therefore essential for OWF planners, developers and 
contractors to understand the uncertainty of expected durations for a given OSP installation scenario.

Barlow et al. [2] present a simulation tool to model the OWF installation logistics problem. The simulation tool is capable of analysing installation vessel scheduling, installation fleet composition and port selection for the installation of all major components of an OWF. The tool incorporates a model of the installation process developed in collaboration with a group of OWF installation industry experts, and a synthetic hourly weather time-series model generated from real data. This combination enables a detailed and realistic assessment of the expected duration and costs associated with a particular installation scenario which provides a framework for detailed analysis of the impact of logistical installation decisions. In this paper the simulation model developed by Barlow et al. [2] is used to explore logistical decisions concerning the installation of OSPs on a fictional case-study of an OWF installation which is designed to be representative of the next phase of OWFs to be installed in Europe.

\section{RELEVANT LITERATURE}

Other studies on the logistics of OWF installation are to the best of our knowledge limited to the following recent papers. In [12] the short-term vessel planning for the installation of an offshore wind farm is investigated. They use a mixed-integer linear programming model which takes weather forecast as an input rather than directly incorporating the uncertainty. A single installation vessel and four operations related to the installation of 12 turbine substructures and WTGs are considered. Three scenarios of vessel scheduling are considered in the model. In [7], a two-level simulation which has a port inventory control system coupled with a reactive scheduling component is used to determine loads and operations based on forecast weather conditions. They incorporate a medium-term weather forecast to determine the installation schedule which is updated with a short-term forecast, and five categorical weather states are considered ranging from very bad to very good. A single vessel is considered to perform all installation operations. Seven installation operations are considered and the focus of this work is on the effect that different levels of inventory have on the progress of the installation of 12 turbine substructures and WTGs and the resulting duration. Similarly to [12], the problem is framed as a mixed-integer linear programming model in [1] with five categorical weather states. The proportion of occurrence of each weather state is determined beforehand and fed into the optimisation model. In this case ten installation operations are considered related to the installation of turbine substructures, WTGs and interarray cables. Three different types of vessel are potentially used to complete different categories of the ten installation tasks. Three vessel scheduling scenarios are considered for the installation of 30 turbines. In comparison with the works [1], [7], [12], the model developed by Barlow et al. [2] provides a more realistic representation of the installation process. Additionally, Barlow et al [2] provide a comprehensive review of the small number of studies concerning offshore support vessels for the oil and gas industry, which have several similarities with the problem discussed here. In these problems the offshore supply vessels have a series of operations which must be completed, where these operations are subject to weather limitations. To the best of our knowledge, no studies on the logistics of OSP installation have been published previously.

\section{OFFSHORE WIND FARM INSTALLATION LOGISTICS MODEL}

The tool developed in Barlow et al. [2] for simulating the impact of an OWF installation logistics scenario is employed here. A brief description of the relevant components of this tool is presented below; for a full description see [2].

The installation model in [2] is developed through close collaboration with experts from three companies with direct experience of the European OWF industry, with a particular emphasis on providing an accurate representation of the current industry practices and experiences. The model is designed to cover the main aspects of an OWF installation with a detailed breakdown of the associated installation tasks and the flexibility to model the wide variety of installation scenarios which could potentially be considered for current and future OWF developments.

A high-level overview of a standard component installation for an OWF is displayed in the flowchart of Figure 1 with the key installation operations and their precedence relationships identified. Each individual operation will have a specific set of operational limits including daylight and weather restrictions which are dependent on the operation and the particular vessel used. The OSP installation includes the installation of the OSP foundations, piles and jackets, and the OSP topsides; each component installation follows the general structure given in Figure 1. The OSP foundations are installed either through a pre-piling or post-piling approach, and once foundation installation is complete grouting is required to secure the structure. Grouting may be performed by an installation vessel, in which case the duration of the installation is adjusted accordingly. Alternatively, grouting may be carried out as a support operation performed by a separate vessel, in which case the grouting immediately follows the completion of the foundation installation. The foundation installation is considered to be complete two days after the grouting operations are completed to allow time for the grout to set. Topside installation has several associated support operations including mechanical completion, electrical completion and commissioning. Each of these operations requires the transfer of technicians on and off the OSP using crew transfer vessels, and these transfers are 
incorporated in the durations and weather limits of the respective operations. The foundation installation is required to be complete prior to installation of the topside. Various modes of operation for OSP installation

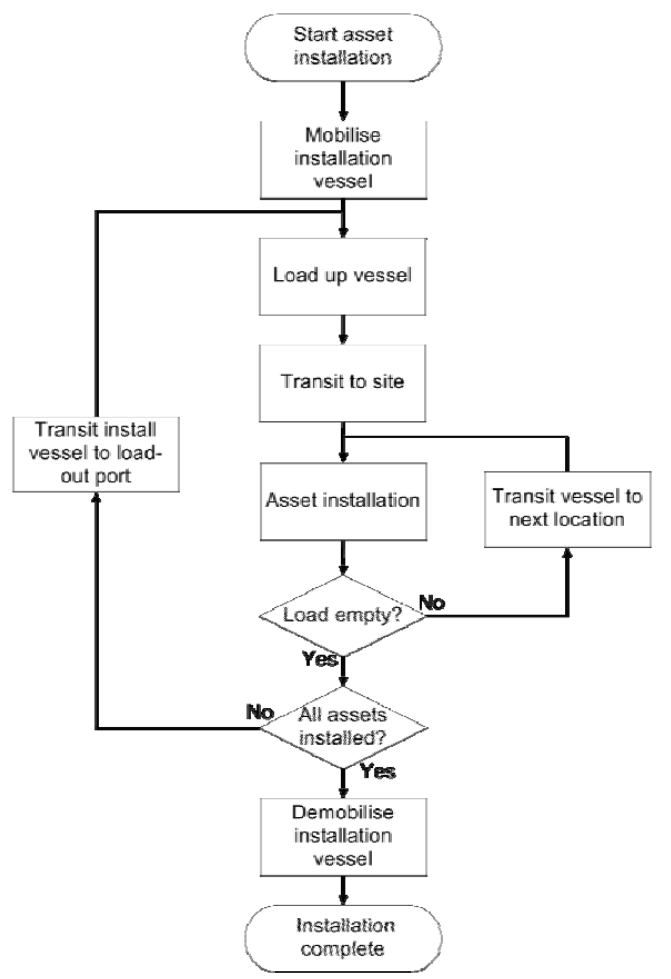

Fig. 1 Flow-chart for the installation of each category of substation component

vessels are supported, including multiple vessels per component-type, single vessels used for multiple types of component installation with or without remobilisation, and vessels supported by supply barge. Additionally, OSP installation vessels and barges may carry multiple categories of component in a single load, such as piles and jackets. The number of options available are required to provide a realistic representation of the OSP installation, where due to the small number of components involved (typically less than five OSPs) the installation process is more flexible than for example with the wind turbine installation (potentially hundreds of components).

The uncertain weather conditions are modelled through a correlated auto-regression model, similar to the approach taken in [4]. This enables multiple data-sets of synthetic weather data to be generated from a hindcast weather data-set, which retain the underlying statistical properties of the original data-set. The weather properties included here are significant wave height and wind speed, which can be appropriately correlated in the synthetic weather data-sets.

An installation scenario is assessed by simulating the progress of the installation subject to each synthetic weather series. Simulating this progress over many synthetic weather series provides a realistic assessment of the expected duration and thus the expected costs of the installation. Ross [11] provides a general discussion of applying simulation models to real-world problems and gives an introduction to various simulation methods. Probabilistic performance measures used to evaluate an installation scenario include a cost breakdown of the installation, the expected duration of each installation operation and expected delays during the installation

\section{RESULTS}

A fictional OWF installation has been designed as a casestudy which is intended to be representative of the next phase of European OWFs to be developed. The site is located in the North Sea 80 NM off the East coast of the UK with an average water depth at the site of $50 \mathrm{~m}$. The site has 350 turbines with a capacity of $6 \mathrm{MW}$ giving a total of $2.1 \mathrm{GW}$ generating capacity. Four OSPs are employed to transmit the generated power to shore, each consisting of a single topside section situated upon two jackets, each of which is secured with 8 piles. The jackets and piles are fabricated at the same port which is located $300 \mathrm{NM}$ from the OWF site and are transported directly from here to the site for installation. The topsides are shipped to a marshalling port located $100 \mathrm{NM}$ from the OWF site and transported from here to the site for installation.

To demonstrate the potential decision support provided by the OWF installation logistics simulation tool outlined in Section 3, the three distinct installation vessel scenarios which may be pursued by OWF developers are investigated, and the impact of each of these scenarios on the cost and duration of the OSP installation is explored. The first scenario is that three separate installation vessels are used to install the four OSPs, with a separate vessel installing each of OSP jackets, OSP piles and OSP topsides. The second scenario is that a single installation vessel installs all four OSPs, installing jackets and piles at each location in turn, then returning to each location to install topsides. This rotation allows the grouting which secures the piles to the base of the jacket to cure at each location before installing the topside structure. The third scenario also uses a single vessel for the installation of jackets, piles and topsides, although in this case there is a focus on completing the first OSP so that the OWF can begin to generate profits from power production. This is achieved by first installing jackets, piles and topside at the first OSP location, then proceeding as with the second scenario where jackets and piles are installed consecutively at each of the remaining OSPs in turn, before returning to these to install the topsides. In each case the installation vessel(s) are supported by a number of supply barges, where the capacity of barges is such that a single barge can carry either 16 piles, two jackets, 
or one topside; no composite-load barges are considered. Each installation scenario is improved such that the logistical decisions regarding the number of supply barges used with each type of component and the mobilisation dates for installation vessels and supply barges are selected to provide the best combination of cost and duration of the installation. For each installation vessel scenario, each combination of supply barge values and each mobilisation date is investigated over 100 simulations of synthetic weather series. The relevant costs are assumed to be an average £10k day-rate for every supply barge used, £100k day-rate for the separate piling installation vessel, £160k day-rate for the separate jacket installation vessel, £200k day-rate for the separate topside installation vessel and for the installation vessel in the single-vessel scenarios, and £500k annual port costs which are calculated proportionately for the duration of use. The costs associated with support operations following the topside installation, such as completion operations and commissioning, are neglected as these can be expected to be consistent across both installation scenarios. The supply rate of each component is controlled such that the installation will not be delayed at any point by a lack of available loads. All vessels used are assumed to be high-performance vessels which will require similar durations to complete equivalent operations. The mobilisation of the jacket installation vessel in each scenario is activated on the $1^{\text {st }}$ of April the first installation vessel which is required to operate under a post-piling foundation approach. In this way the comparisons between each installation scenario are equitable, and each scenario is measured according to its operational merits and robustness to uncertain weather conditions.

Data from the FINO1 weather station [3] is used to generate the synthetic weather series as described in Section 3; the FINO1 weather station is an offshore weather research platform located in the North Sea 45 $\mathrm{km}$ off the coast of Germany with high-quality publicly available weather time-series recorded since 2003. Due to differences in location and proximity to shore, weather conditions recorded at FINO1 may not be representative of weather conditions at specific UK Round 3 and Scottish territorial OWF sites; however, this data-set enables the capability of the simulation tool to be demonstrated in the analysis presented here without recourse to site-specific weather data.

The key considerations for an OWF developer are to minimise installation costs and to achieve export of generated power as quickly as possible to maximise production benefits. Installation costs are minimised by reducing the operational duration of installation vessels and barges, which will provide an associated reduction on the port costs. The ability to export generated power requires the completion of the OSPs. In practice the online generating capacity of the OWF will increase steadily over the entire installation process as the various stages of installation for the 350 turbines are completed over a period of years. It is therefore important to have the first OSP completed as soon as possible to have exporting capability, with less pressure on the completion of the remaining OSPs to facilitate the steadily increasing levels of generating capacity. The measures of total installation costs and date of completion of first OSP are therefore used here to finetune each of the three vessel scenarios. With the threevessel installation scenario, the date component installation operations are completed on the last OSP is used as an additional measure of the progress of each component installation; however, as discussed this is of secondary concern.

\subsection{THREE-VESSEL SCENARIO}

INSTALLATION

The number of supply barges supporting each installation vessel in the three-vessel scenario is selected to minimise cost and duration. Options considered are as follows: one or two barges supporting the pile installation vessel; two, three or four supply barges supporting the jacket installation vessel; and two, three or four supply barges supporting the topside installation vessel. Figures 2-4

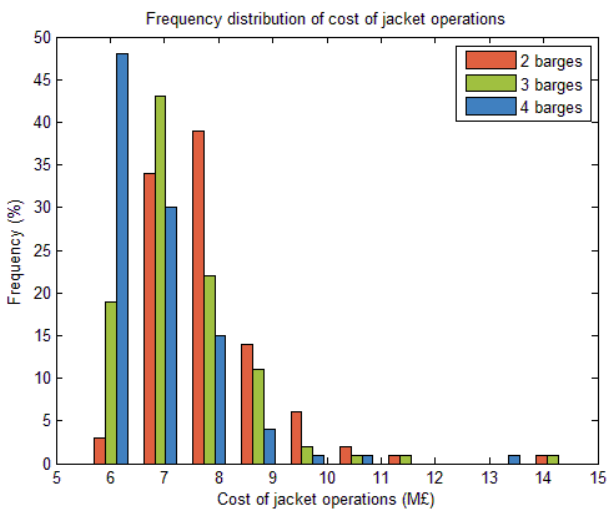

(a)

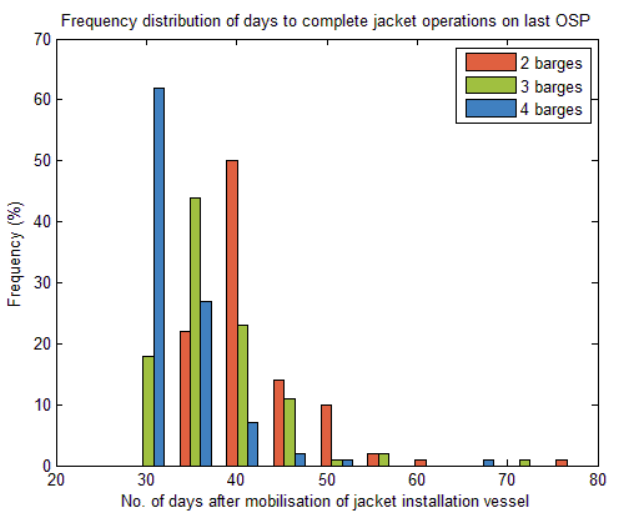

(b)

Figure 2: (a) cost of jacket installation operations and (b) completion date for jacket installation operations on the last OSP, for two, three and four jacket supply barges 


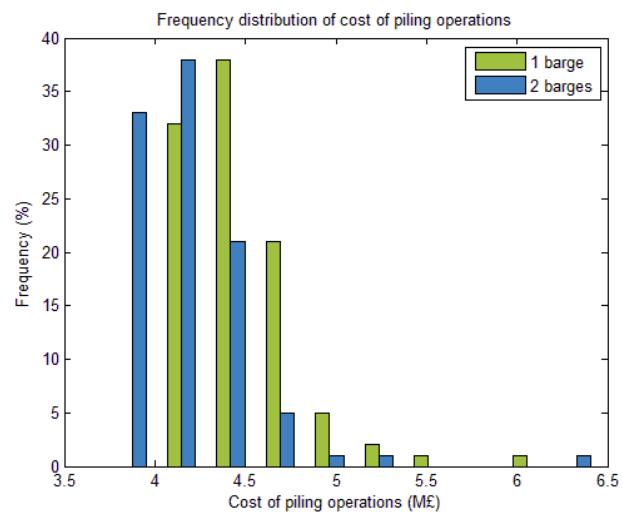

(a)

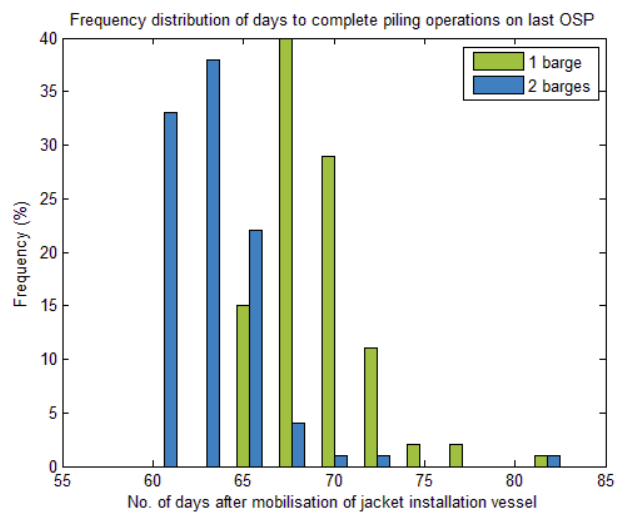

(b)

Figure 3: (a) cost of pile installation operations and (b) completion date for pile installation operations on the last OSP, for two and three pile supply barges.

display the variation of costs and durations for each of these options, where costs are restricted to the particular type of component under consideration and duration is measured by the date at which operations on the last OSP are completed for each type of component. Figure 2 clearly demonstrates that both cost and completion of jacket operations are minimised by employing four barges to support jacket operations, and that this decision could save on average $£ 1 \mathrm{M}$ and 10 days of operations in comparison with a two barge approach. A similar comparison is evident in Figure 3 where one or two pile supply barges are considered. It is clear that using two barges minimises both cost and completion date of pile operations, giving an average saving of £270k and 5 days of operations. With regard to the number of topside supply barges used, Figure 4 shows that each of the approaches considered has merits. Figure 4(a) shows that there is not a great deal of variation in cost between using two, three or four topside supply barges. A closer analysis is provided in Table 1 for both costs and times for completion of operations.

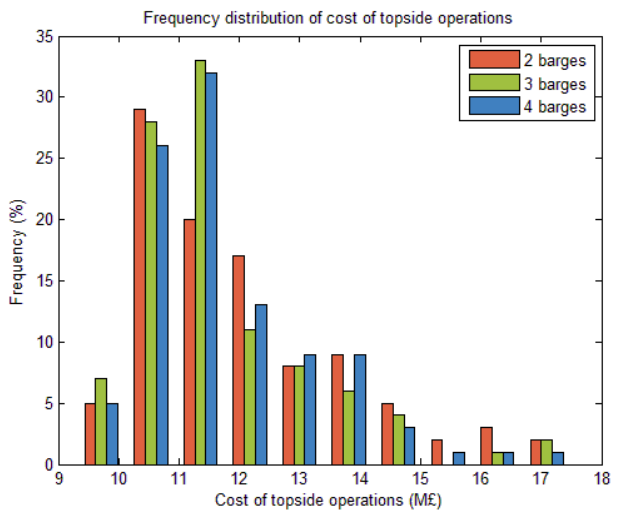

(a)

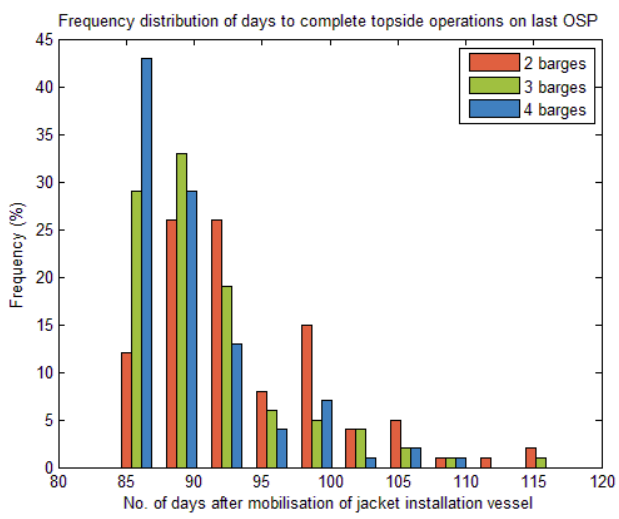

(b)

Figure 4: (a) cost of topside installation operations and (b) completion date for topside installation operations on the last OSP, for two, three and four topside supply barges.

Table 1: Median and 90\% confidence interval for the cost and duration of topside installation operations with two, three and four supply barges.

\begin{tabular}{|c|c|c|c|c|c|c|}
\hline \multirow{2}{*}{$\begin{array}{c}\text { No. of } \\
\text { barges }\end{array}$} & \multicolumn{3}{|c|}{$\begin{array}{c}\text { Topside installation } \\
\text { costs (£M) }\end{array}$} & \multicolumn{2}{c|}{$\begin{array}{c}\text { Completion of topside } \\
\text { operations at last } \\
\text { OSP (days) }\end{array}$} \\
\cline { 2 - 7 } & \multicolumn{3}{|c|}{ Percentile } & \multicolumn{3}{c|}{ Percentile } \\
\cline { 2 - 7 } & 5 th & 50 th & 95 th & 5 th & 50 th & 95 th \\
\hline 2 & 10.12 & 11.54 & 15.61 & 86.79 & 92.33 & 106.69 \\
\hline 3 & 9.76 & 11.30 & 14.48 & 84.81 & 89.17 & 102.54 \\
\hline 4 & 10.00 & 11.43 & 14.54 & 84.38 & 87.94 & 99.38 \\
\hline
\end{tabular}

Table 1 reveals that the three barge approach is the cheapest overall, providing an average saving of $£ 240 \mathrm{k}$ in comparison with the two barge approach. From Figure 4(b) it is clear that the four barge approach provides the quickest installation duration, with three barge and two barge approaches causing slightly longer installations. Table 1 demonstrates, however, that the three barge approach is comparable; the reduction in completion date for OSP topside operations with a four barge approach compared to a three barge approach is only one day on average. The three supply barge approach is taken here for topside installation as this provides the best return for 
cost of operations and provides a completion of operations only one day longer than the four barge approach. The best combination of completion of operations and cost is therefore taken as four barges for jacket supply, one barge for pile supply, and three barges for topside supply. Any number of supply barges used will enable installation operations at the first OSP to be completed at the same rate, and so this is not discussed above.

The mobilisation of each set of installation vessels and supply barges is then investigated to minimise the costs and duration of the installation. The first step is to identify the appropriate staggering of mobilisation of supply barges in relation to the respective installation vessels. This is achieved by mobilising the supply barges at the latest date which does not affect the operations of the related installation vessel. It is found that jacket supply barges should be mobilised 2 days before the jacket installation vessel, pile supply barges should be mobilised 6 days after the pile installation vessel, and topside supply barges should be mobilised 3 days after the topside installation vessel is mobilised.

The relative mobilisation dates of the installation vessels are then investigated, with the relationship between supply barge and installation vessel mobilisation dates as defined above. In Figure 5(a) the mobilisation of the pile installation vessel is varied with respect to the mobilisation date of the jacket installation vessel. With comparatively late mobilisation dates, the pile installation vessel will not be influenced by the progress of the jacket installation vessel and therefore the duration and cost of the piling installation operations are relatively consistent from approximately six days after the mobilisation of the jacket installation vessel. Over this period, however, the installation operations at the first and last OSP increase as a direct consequence of beginning later. With comparatively early mobilisation dates, the pile installation vessel will immediately follow the jacket installation vessel, and will therefore be very sensitive to the progress of the jacket installation and likely to experience delays. Consequently, the completion of operations is relatively consistent until mobilising approximately two days after the jacket installation vessel; however, the operational costs over this period are higher due to the delays experienced, and as the pile mobilisation date increases the delays experienced and operational costs decrease. A pile installation vessel mobilisation date four days after the jacket installation vessel is selected here, as this provides a combination of low operational costs through low delays and early completion dates of piling operations. A similar approach is then taken with the mobilisation date for the topside installation vessel, as shown in Figure

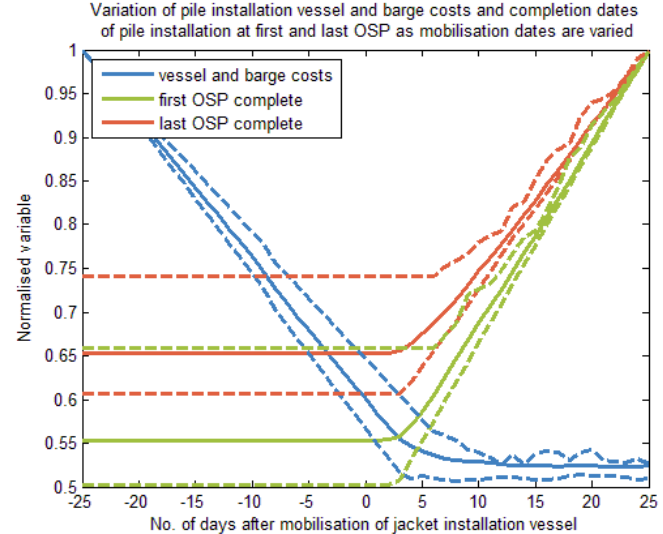

(a)

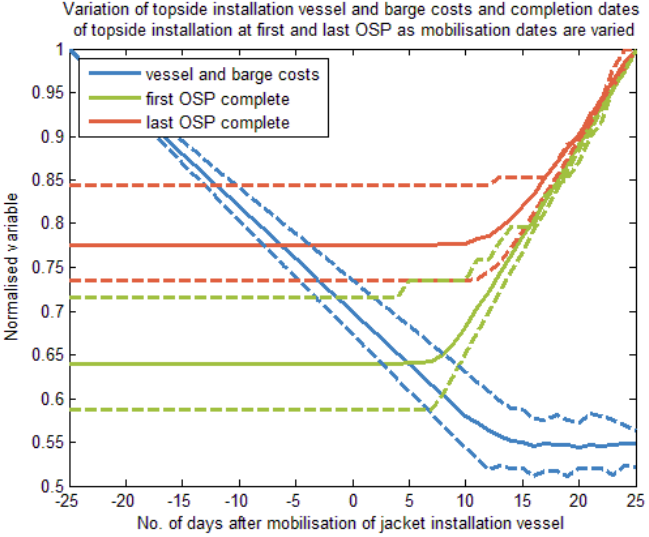

(b)

Figure 5: Median and 90\% confidence intervals for the costs of installation operations and the completion dates of operations for (a) pile installation, and (b) topside installation, as the mobilisation date of installation vessel are varied

5(b). In this case a topside vessel mobilisation date up to approximately seven days after the jacket installation vessel shows a relatively consistent date for completion of topside operations, and a decreasing cost of operations as delays are reduced. A topside installation vessel mobilisation date more than 13 days after the jacket installation vessel shows a relatively consistent cost of operations, as over this period delays due to the progress of the jacket and pile installations are minimal and any delays will be largely due to the uncertain weather conditions. Over this period, however, the completion date for topside operations increases due to the later start date. A topside installation vessel mobilisation date of 10 days after the jacket installation vessel is taken here as this provides a combination of relatively low cost through minimal delays, and relatively early completion of topside operations. The best combination of operational duration and costs is therefore given by the mobilisation date breakdown given in Table 2 . 
Table 2: Mobilisation dates of each installation vessel and each group of supply barges, given relative to the mobilisation date of the jacket installation vessel

\begin{tabular}{|l|c|}
\hline \multicolumn{1}{|c|}{ Vessel } & $\begin{array}{c}\text { Mobilisation date relative } \\
\text { to jacket installation vessel }\end{array}$ \\
\hline Jacket installation vessel & $\left(1^{\text {st }}\right.$ April $)$ \\
\hline Jacket supply barges & 2 days before \\
\hline Pile installation vessel & 4 days after \\
\hline Pile supply barges & 10 days after \\
\hline Topside installation vessel & 10 days after \\
\hline Topside supply barges & 13 days after \\
\hline
\end{tabular}

\section{2}

\section{SINGLE-VESSEL SCENARIOS}

A similar approach to that described in Section 4.1 is followed for installation scenarios 2 and 3 to define the number of barges used for the supply of each component and for the mobilisation dates of the barges, given that mobilisation of the installation vessel is on the $1^{\text {st }}$ April; for brevity the analysis is omitted here. It is found that the best combination of supply barges for the standard single-vessel installation scenario is for three supply barges supporting jacket installation, one supply barges supporting pile installation and three supply barges supporting topside installation. The breakdown of mobilisation dates for each set of supply barges is given in Table 3. In comparison with Table 2, the topside supply barges are mobilised substantially later as a result of the installation vessel first installing all jackets and piles before topside installation begins.

Table 3: Mobilisation dates for each group of supply barges, given relative the mobilisation date for the installation vessel, for installation scenario 2 (singlevessel approach).

\begin{tabular}{|l|c|}
\hline \multicolumn{1}{|c|}{ Vessel } & $\begin{array}{l}\text { Mobilisation date relative } \\
\text { to jacket installation vessel }\end{array}$ \\
\hline Installation vessel & $\left(1^{\text {st }}\right.$ April $)$ \\
\hline Jacket supply barges & 1 day after \\
\hline Pile supply barges & 10 days after \\
\hline Topside supply barges & 39 days after \\
\hline
\end{tabular}

The best combination of supply barges for the singlevessel installation scenario with focused completion of the first OSP is found to be two supply barges supporting jacket installation, one supply barge supporting pile installation and two supply barges supporting topside installation. The breakdown of mobilisation dates for each set of supply barges is given in Table 4. The different requirement of supply barges and selection of mobilisation dates in comparison with the standard single-vessel scenario is due to the different pressures on the installation scenarios when the complete installation of the first OSP is required at an earlier date.
Table 4: Mobilisation dates for each group of supply barges, given relative the mobilisation date for the installation vessel, for installation scenario 3 (singlevessel approach with focused completion of first OSP).

\begin{tabular}{|l|c|}
\hline \multicolumn{1}{|c|}{ Vessel } & $\begin{array}{c}\text { Mobilisation date relative } \\
\text { to jacket installation vessel }\end{array}$ \\
\hline Installation vessel & $\left(1^{\text {st }}\right.$ April $)$ \\
\hline Jacket supply barges & 0 day after \\
\hline Pile supply barges & 10 days after \\
\hline Topside supply barges & 14 days after \\
\hline
\end{tabular}

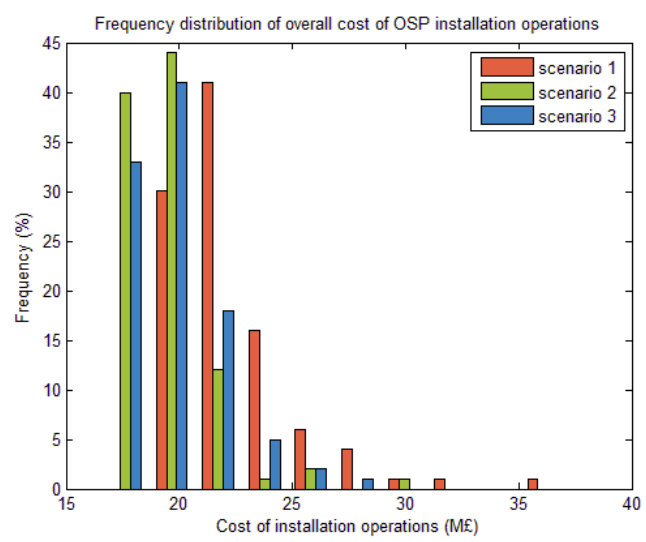

(a)

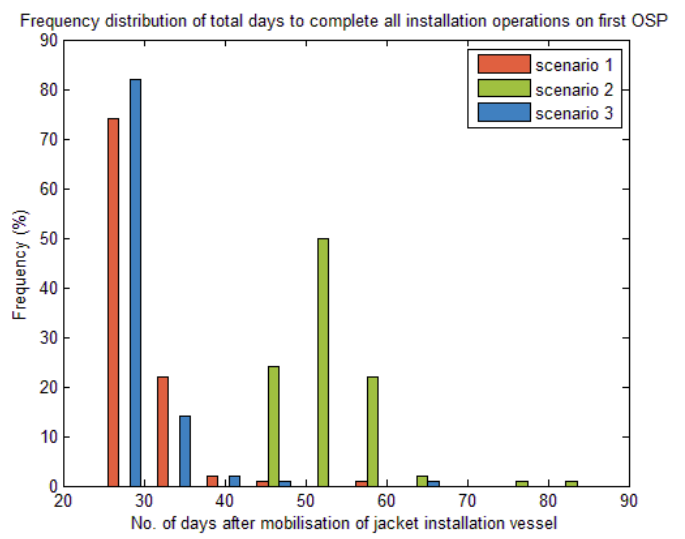

(b)

Figure 6: (a) total cost of installation operations, and (b) total duration of installation operations at the first OSP, with installation scenario 1 (three-vessel approach), installation scenario 2 (standard single-vessel approach) and installation scenario 3 (single-vessel approach with focus on completion of the first OSP).

\subsection{COMPARISON OF INSTALLATION VESSEL SCENARIOS}

Figure 6 compares the three different installation scenarios over the course of the entire OSP installation, where each scenario is fine-tuned as discussed in Sections 4.1-4.2 and further analysis is provided in Table 5 . The three-vessel installation scenario performs well in terms of duration with the first OSP completed on average in $43 \%$ of the time required with the standard 
Table 5: Median and 90\% confidence interval for the installation costs and date of completion for first OSP, with installation scenario 1 (three-vessel approach), installation scenario 2 (standard single-vessel approach) and installation scenario 3 (single-vessel approach with focus on completion of the first OSP).

\begin{tabular}{|l|c|c|c|c|c|c|}
\hline \multirow{4}{*}{$\begin{array}{c}\text { Installation } \\
\text { vessel } \\
\text { approach }\end{array}$} & \multicolumn{3}{|c|}{$\begin{array}{c}\text { Total cost of } \\
\text { installation } \\
\text { operations (£M) }\end{array}$} & \multicolumn{2}{c|}{$\begin{array}{c}\text { Completion of } \\
\text { all installation } \\
\text { operations at first } \\
\text { OSP (days) }\end{array}$} \\
\cline { 2 - 7 } & \multicolumn{3}{|c|}{ Percentile } & \multicolumn{4}{c|}{ Percentile } \\
\cline { 2 - 7 } & $5^{\text {th }}$ & 50 th & $95^{\text {th }}$ & $5^{\text {th }}$ & 50 th & $95^{\text {th }}$ \\
\hline Scenario 1 & 19.35 & 21.36 & 27.19 & 28.13 & 29.13 & 36.23 \\
\hline Scenario 2 & 16.99 & 18.95 & 22.50 & 46.54 & 51.35 & 60.42 \\
\hline Scenario 3 & 17.55 & 19.29 & 23.05 & 24.5 & 26.69 & 34.62 \\
\hline
\end{tabular}

single-vessel scenario. Some improvement is perhaps expected here due to the potential for parallelisation of installation operations; however, this reduction substantially improves the potential for production profits and may render the single-vessel approach undesirable. Additionally the three-vessel approach continues to perform well throughout the entire OSP installation, with an average completion date for the last OSP of 39 days in comparison to approximately 60 days for both single-vessel installation scenarios. The standard single-vessel scenario performs better in terms of the total cost of the installation, with an average reduction of $11.3 \%$ in comparison with the three-vessel scenario and less variation as evidenced by the range of the respective $90 \%$ confidence intervals. This reduced cost is perhaps surprising given the smaller duration required by the three-vessel approach and the lower day-rates for the individual pile and jacket installation vessels, however, the three-vessel is supported with more supply barges. Naturally the third scenario, which employs a single installation vessel with focused installation of the first OSP, improves this completion date; however, the reduction is substantial and the completion date achieved through the third scenario is additionally shown to improve on the three-vessel scenario. Furthermore, focusing on the completion of the first OSP incurs an average increase of only $1.8 \%$ in terms of the installation costs.

\subsection{DISCUSSION}

Each of the installation vessel scenarios compared in Section 4.3 is shown to be advantageous under different measures; the standard single-vessel scenario performs best in terms of the overall installation costs, whereas a slight increase in cost can provide substantial reductions in terms of the completion date for the first OSP. The three-vessel approach is out-performed in terms of both installation costs and the completion of the first OSP; however, this scenario delivers the completion of all four OSPs in substantially less time than the single-vessel scenarios. Depending on the specific OWF installation to be investigated, the requirements and preferences of a developer will vary, and employing a similar analysis to that presented here would arm a developer with the information required to methodically compare the available installation decisions and to identify the most appropriate. It is worth emphasising that the logistical decisions governing the numbers of supply barges used for each component and mobilisation dates of installation vessels and barges were defined here with equal consideration given to both cost and completion date for the first OSP. In practice a developer would fine-tune the relevant installation scenarios subject to their preferences, and there would be potential, for example, for the three-vessel installation scenario to be delivered at a reduced cost and increased completion date for the first OSP if installation cost was the key consideration.

It should be noted that the analysis and results presented in Sections 4.1-4.3 are specific to the fictional case study which is outlined at the start of Section 4, and the comparative performance of the three installation vessel scenarios compared here will vary as the details of the OWF to be developed, the capabilities of the installation vessels and the associated costs are varied. Furthermore, it is worth noting that the case study scenario is somewhat simplified for the purposes of illustration. In addition to the logistical costs related to the installation, an OWF developer will give consideration to the capital expenditure related to acquiring the OSP components. For example, a single OSP can be expected to cost in the region of $£ 50$ million [14]. It may therefore be desirable for an OWF developer to stagger the installation of the OSPs such that each OSP is only installed as required based on the progress of the associated WTGs, rather than installing all OSPs over the same period. Nonetheless, the analysis presented here demonstrates, the potential decision support provided through this simulation tool; this analysis could quickly be extended to investigate alternative vessel costs and operational capabilities, to explore the financial implications of staggering the OSPs installations, or to reconsider the entire OWF installation process.

\section{CONCLUSIONS}

This paper presents the application of an offshore wind farm (OWF) simulation tool to a case study installation project. The simulation tool combines a realistic model of an OWF installation developed through collaboration between academic and industrial partners, with a synthetic weather model which enables a realistic assessment of the duration of the OWF installation and associated costs. The case study presented here is used to demonstrate the impact of three installation vessel 
scenarios during the installation of the offshore substation platforms at the site. This application demonstrates the potential of the simulation tool to provide OWF planners with a framework to compare the impact of various installation scenarios in terms of the duration and costs of the installation.

The study presented here is part of a larger project investigating decision support for the installation of OWFs. This project has developed two complimentary tools for decision support: a simulation tool and an optimisation tool. Interested readers can see [2] and [13] for further information on each tool, respectively.

\section{ACKNOWLEDGEMENTS}

This study was funded through the University of Strathclyde Technology and Innovation Centre, grant reference TIC/LCPE/FI03. The authors would like to thank Scottish Power Renewables, Scottish and Southern Energy Renewables and Technip Offshore Wind Limited for their contribution.

\section{REFERENCES}

1. AIT-ALLA, A., QUANDT, M., LUTJEN, M., 'Aggregate Installation Planning of Offshore Wind Farms', in Proceedings of the 7th International conference on communications and information technology. 2013. Cambridge, MA, USA.

2. BARLOW E., TEZCANER OZTURK D., DAY A. H., BOULOUGOURIS E., REVIE M., AKARTUNALI K. 'Simulation of the offshore wind farm installation logistics problem', In preparation.

3. Bundesamt fur Seeschifffahrt und Hydrographieis FINO database, available from: http://www.fino1.de/en/

4. DINWOODIE, I., QUAIL, F., MCMILLAN, D., 'Analysis of Offshore Wind Turbine Operation and Maintenance Using a Novel Time Domain Meteo-Ocean Modeling Approach', in ASME Turbo Expo 2012: Turbine Technical Conference and Exposition, Copenhagen.

5. EUROPEAN WIND ENERGY ASSOCIATION, 'Wind in our sails', 2011. Accessed on 30th July 2014 from: http://www.ewea.org/publications/reports/windin-our-sails/.

6. EUROPEAN WIND ENERGY ASSOCIATION, 'Deep Water', 2013. Accessed on 30th July 2014 from: http://www.ewea.org/publications/reports/deepwater/.

7. LÜTJEN, M., KARIMI, H.R., 'Approach of a Port Inventory Control System for the Offshore Installation of Wind Turbines', in The Twenty- second International Offshore and Polar Engineering Conference, 2012, Rhodes, Greece.

8. OFFSHORE WIND COST REDUCTION TASK FORCE, 'Offshore wind cost reduction task force report', 2012. Accessed on 30th July 2014

from: https://www.gov.uk/government/groups/offshor e-wind-cost-reduction-task-force.

9. RENEWABLE UK, 'Wind energy in the UK; state of the industry report', 2013. Accessed on 30th July 2014 from: http://www.renewableuk.com/en/publications/re ports.cfm/state-of-the-industry-report-2012-13.

10. ROBERTS, A., WESTON, J., VALPY, B., 'Offshore wind: a 2013 supply chain health check. A report prepared by BVG associates for the Crown Estate', 2013. Accessed on 30th July 2014 from: http://www.thecrownestate.co.uk/energy-andinfrastructure/offshore-wind-energy/workingwith-us/strategic-workstreams/supply-chainand-skills/.

11. ROSS, S.M., Simulation,. Academic Press, London UK, 2013

12. SCHOLZ-REITER, B., LÜTJEN, M., HEGER, J., SCHWEIZER, A. 'Planning and control of logistics for offshore wind farms', in Proceedings of the 12th WSEAS international conference on Mathematical and computational methods in science and engineering, 2010, Faro, Portugal.

13. TEZCANER OZTURK D., BARLOW E., DAY A. H., BOULOUGOURIS E., REVIE M., AKARTUNALI K. 'A rolling horizon optimisation model for offshore wind farm installation logistics', In preparation.

14. UK CROWN ESTATE, 'A guide to an offshore wind farm', 2010. Accessed on 30th July 2014 from: http://www.thecrownestate.co.uk/energyand-infrastructure/offshore-wind-energy/.

15. UK DEPARTMENT OF ENERGY AND CLIMATE CHANGE, 'UK renewable energy roadmap update 2013', 2013. Accessed on 30th July 2014 from: https://www.gov.uk/government/publications/uk -renewaren-energy-roadmap-second-update

\section{AUTHORS BIOGRAPHY}

Dr Euan Barlow holds the current position of Research Associate at the University of Strathclyde. His previous experience includes developing maintenance decision support systems for energy utilities and modelling stochastic systems. Dr Diclehan Tezcaner Ozturk holds the current position of Research Associate at the University of Strathclyde. She is responsible for developing optimisation methods for the wind farm installation logistics problem. Her previous experience includes studies on multiobjective optimisation, routing problems and combinatorial optimisation problems. 
Sandy Day is Professor of Marine Hydrodynamics in the Naval Architecture Ocean and Marine Engineering Department at the University of Strathclyde, and is the Director of the University's Kelvin Hydrodynamics Laboratory. His research interests lie in computational and experimental hydrodynamics; he is actively engaged in fundamental and industry-focussed research including the performance of offshore renewable energy devices. Dr Evangelos Boulougouris is a lecturer in the Department of Naval Architecture, Ocean and Marine Engineering, University of Strathclyde. His research interests include ship design, survivability, design optimization and seakeeping. Dr Matthew Revie holds the current position of Knowledge Exchange Fellow at the Department of Management Science, University of Strathclyde. He is also Director of Knowledge Exchange in the department and primarily responsible for bridging the gap between academia and industry. Dr Kerem Akartunali is a Senior Lecturer in the Department of Management Science, University of Strathclyde. His research expertise lies in integer optimization and its applications, in particular in production planning and transportation scheduling/planning. 